Senior, V. E. (1959). Can. F. comp. Med. 23, 229.

Shand, A. \& Lewis, G. (1957). Vet. Rec. 69, 618.

Sutter, M. D., Rawson, D. C., McKeown, J. A. \& Haskell, A. R. (1958). Am. F. vet. Res. 119, 890.

Todd, J. R. (1962). Vet. Bull.; Weybridge 32, 573 .

Todd, J. R. \& Gracey, J. F. (1959). Vet. Rec. 71, I45.

Todd, J. R., Gracey, J. F. \& Thompson, R. H. (1962). Br. vet. J. II8, 482.

Todd, J. R. \& Gribben, H. J. (1965). Vet. Rec. 77, 498.

Todd, J. R. \& Thompson, R. H. (1963). Br. vet. F. I19, 161.

Todd, J. R. \& Thompson, R. H. (I964). F. comp. Path. 74, 542.

Todd, J. R. \& Thompson, R. H. (1965). Br. vet. F. I21, 90.

Van Adrichem, P. W. M. (1965). Tijdschr. Diergeneesk. 90, r371.

Wallace H. D., McCall, J. T., Bass, B. \& Combs, G. E. (1960). F. Anim. Sci. r9, I 53.

\title{
Urinary calculi in ruminants
}

\section{By A. C. Field, Moredun Research Institute, Edinburgh}

Urolithiasis is not at present an important problem for the livestock industry in the United Kingdom, but the probable introduction of more intensive systems of management may change this position. The rapid fattening of male animals with high-energy diets predisposes to formation of phosphatic calculi and obstructive urolithiasis in the feed lot system of the USA and it is a form of this type of management which is most likely to be introduced to this country. For this reason, this review will be limited to the problem of phosphatic calculus formation, although other calculi, especially siliceous forms cause economic loss in extensive areas of the world.

Much of the information on urolithiasis in ruminants comes from empirical attempts at reducing the high incidence of calculi associated with the feeding of certain important animal feeding-stuffs in USA. There are few comprehensive experiments designed solely to study the aetiology of calculus formation and data from studies in humans have been used, principally in the section on the theories of calculus formation, despite the frequent species differences in the composition of calculi, in urine $\mathrm{pH}$ and in diets.

\section{Theories of calculus formation}

A satisfactory hypothesis for the aetiology of calculus formation must explain the initiation or nucleation of calculi, their subsequent growth and why they lodge in the kidney or bladder instead of being passed out in the urine. Current hypotheses fall broadly into three categories.

Matrix theory. The urinary macromolecules, collectively known as urinary colloids, have been incriminated in urolithiasis as they are invariable components of the moeity of calculi (Boyce, Garvey \& Norfleet, 1954; Boyce \& Swanson, 1955). In the matrix theory, calculus formation is viewed as a process similar to calcification of cartilage, bone and teeth. Here a precedent matrix provides a specialized medium in which the dissolved calcium, magnesium, phosphate and other ions combine and crystallize to eventually mineralize the matrix. Unfortunately, urinary protein excretion cannot be correlated with the incidence of urinary calculi in ruminants, because 
attempts to produce changes in urinary protein have induced concurrent changes in other urinary components known to affect calculus formation. Stilboestrol implantation of sheep increases urinary protein excretion and also the incidence of calculi (Cornelius, 1963 ; Jordan, 1953), but urethral occlusion in this instance is not due to typical phosphate calculi but to mucoid masses (Marsh, I96I), possibly arising from the excess mucoid secretion from the hyperplastic prostrate gland.

Crystallization-inhibitor theory. Human urine contains a number of normal constituents which can inhibit the formation of hydroxyapatite crystals and the calcifcation of rachitic rat cartilage slices in supersaturated solutions of calcium and phosphorus ions (Thomas \& Howard, I959; Howard, 1962; Fleisch \& Bisaz, 1962). Of the two known types of inhibitors pyrophosphate and peptides, Howard, Thomas, Barker, Smith \& Wadkins ( 1967 ) consider the latter to be the more important. It has also been suggested that urinary colloids may prevent the formation of nuclei and crystal growth and that calculus formation is initiated by a deficiency in these components (Joly, 1939; Puntriano, 1954). Comparable studies on normal urine from ruminants have not been reported.

Hyperexcretion-crystalline theory. From their studies on the growth of artificial concretions in urine Vermeulen, Lyon \& Fried $(1965)$ concluded that calculus formation is basically a process of crystallization and the matrix serves as a binding material holding the calculi together. Basically crystallization requires two conditions: some degree of supersaturation and some type of nucleation. A urine is supersaturated with respect to a calculus-forming salt when the product of the relevent ion concentrations (or more accurately ion activities) exceeds the solubility product of the salt. The formation product of a salt, on the other hand, is the product of the activities of the ions at which precipitation spontaneously occurs in the supersaturated solution of the salt (Nordin \& Robertson, 1966). Nucleation in otherwise stable supersaturated solutions may be induced by foreign bodies, any crystals already present or through a variety of surface phenomena.

For a proper appreciation of the aetiology of calculus formation in ruminants and for a more logical approach to prophylactic measures, a knowledge of the activity products in ruminant urine of the calculus-forming salts in relation to their solubility and formation products is required. The calculus-forming salts in ruminants are magnesium ammonium phosphate, calcium and magnesium phosphate, and the concentration of ionized calcium, magnesium and phosphate must, therefore, be known. At present it is not possible to measure these concentrations directly, but the introduction of new techniques such as ion specific electrodes and more sophisticated indirect methods (Robertson, Peacock \& Nordin, 1968) hold promise for the future. However, knowledge of solubility theory gives an appreciation of the complexity of the problem of calculi formation, of the number of measurements required to characterize urine with respect to calculus formation and provides a framework for the planning of future experiments.

In the past, much of the experimental information on urolithiasis in the ruminant has been contradictory and the differences impossible to explain because of the few parameters measured. 


\section{Factors affecting incidence of calculi}

Hydrogen ion concentration. The activity products of the calculus-forming salts in ruminants will be very dependent on urine $\mathrm{pH}$ by virtue of the triphosphate ion (Robertson et al. I968). Urine $\mathrm{pH}$ is not invariably reported; its measurement in ruminants presents problems because of the volatile component of the buffer system, carbonic acid (Udall \& Chen Chow, 1963 ). The $\mathrm{pH}$ of urine from ruminants varies widely with the type of feeding, but is generally alkaline $(7 \cdot 8-8 \cdot 5)$. However, F. G. Whitelaw (personal communication) found low values $\left(5^{\cdot 2-7} \cdot 7^{\circ}\right)$ in urine from cows and fattening cattle given an all-barley diet, a type of diet which is not associated with a high incidence of urolithiasis. Bushman, Embry \& Emerick (1967) have found that ammonium chloride ( $1 \cdot 5 \%$ ) added to a calculogenic diet (i.e. a diet which produces a high incidence of calculi) reduced the $\mathrm{pH}$ of urine from between $7 \cdot 85$ and 8.55 to 6.43 and reduced the incidence of calculus in sheep. The lowered $\mathrm{pH}$ will reduce the degree of saturation of urine with calcium phosphate and magnesium ammonium phosphate and Elliot, Quaide, Sharp \& Lewis (1958) claim that the latter is not precipitated from human urine with a $\mathrm{pH}$ less than $7 \cdot \mathrm{I}$. Udall (I962) on the other hand, produced a significant difference in urine $\mathrm{pH}$ by feeding phosphoric acid and potassium carbonate without affecting the incidence of calculi in lambs. Unfortunately, interpretation of his results is complicated by failure to quote the actual values for the $\mathrm{pH}$ of urine on the two treatments, the phosphoric acid possibly influencing the incidence of calculus through increased excretion of phosphate in urine and the change in urine $\mathrm{pH}$ possibly altering the type of calculus produced.

Urinary phosphorus. There are large differences in the total excretion of phosphorus and in susceptibility to calculus between sheep on a calculogenic diet. Packett $\&$ Hauschild (1964) found that those sheep which developed calculus had a higher concentration of and excreted more phosphorus in their urine than non-affected sheep. Robbins, Kunkel \& Crookshank ( $\mathrm{r}_{965}$ ) confirmed this finding and showed also that there was no similar difference in urine $\mathrm{pH}$. Since the degree of ionization of phosphate to the trivalent phosphate ion in urine is very dependent on $\mathrm{pH}$, the above finding suggests a positive correlation between calculus formation and the concentration of the trivalent phosphate ion. Increasing the dietary intake of phosphorus in general increases the output and concentration of phosphorus in urine (Elam, Ham \& Dyer, 1959; Bushman, Emerick \& Embry, 1965) and the incidence of calculus in ruminants given a calculogenic diet (Bell \& Kirk, r935; Lindley, Taysom, Ham \& Schneider, I953; Emerick \& Embry, 1963). There is not, however, an absolute relationship between the concentration or the total amount of phosphorus in urine and the incidence of calculi. Robbins et al. (1965) found that levels of urinary phosphorus associated with calculi in one experiment were not in another. The high incidence of calculi in sheep associated with the feeding of high levels of phosphorus $(0.62$ and $0.81 \% \mathrm{P})$ can be reduced by giving additional calcium in the diet (Emerick \& Emery, 1963, 1964). Gill, Finlayson \& Vermeulen (1959) have suggested that the additional calcium reduces the incidence of calculi in rats by impairing phosphorus absorption from the gut. Field \& Suttle (unpublished) could find no evidence for this effect in sheep over a wide range of dietary intakes of calcium. 
Urinary magnesium. Magnesium is an invariable component of phosphatic calculi in ruminants (Cornelius, Moulton \& McGowan, 1959; Robbins et al. 1965; Packett \& Coburn, 1965), and urine from sheep with urolithiasis must be supersaturated with calculus-forming magnesium salts. Packett \& Hauschild (I964) found no correlation and Robbins et al. (1965) a negative correlation between the concentration or amount of magnesium in urine and the occurrence of calculi in sheep given a calculogenic diet. Since a negative correlation is difficult to understand, it probably arose by chance through magnesium being negatively correlated with phosphorus in urine (Crookshank \& Robbins, 1962) which is itself correlated with urolithiasis. Robertson et al. (1968) found in humans that females who developed magnesium ammonium phosphate type of calculus had a lowered urinary excretion of magnesium. These findings suggest that magnesium plays only a minor part in the formation of phosphatic calculi.

Urinary calcium. Ca is usually found in phosphatic calculi of ruminants but the amount is small and variable (Cornelius et al. 1959; Robbins et al. 1965; Packett \& Coburn, 1965). The salt of calcium and phosphate which is found in phosphatic calculi in ruminants is unknown. In man, it is usually thought to be octocalcium phosphate $\left(\mathrm{Ca}_{4} \mathrm{H}\left(\mathrm{PO}_{4}\right)_{3}\right)$ (McGregor, Robertson \& Nordin, I 965), but in old stones the salt may be hydroxyapatite $\left(\mathrm{Ca}_{5}(\mathrm{OH})\left(\mathrm{PO}_{4}\right)_{3}\right)$ (Robertson et al. I968). Robbins et al. (1965) found that the calculi in their experiments contained about $4 \%$ calcium and that there was no difference in general in urinary calcium excretion between sheep which developed calculi and healthy sheep. Packett \& Hauschild (I964) obtained a similar result, which suggests that on the calculogenic type of diets used by experimenters in USA, urine of sheep is rarely saturated with calcium phosphate. It is possible that with the introduction of diets which lead to acid urines, the slowgrowing calcium phosphate type of calculus found in humans may predominate when it occurs, rather than the rapidly produced magnesium containing phosphatic calculus now found.

Urinary ammonium. The level of the ammonium ion in urine from ruminants and its importance in the formation of magnesium ammonium phosphate type of calculus has received little attention. J. S. Slater (private communication) found that the concentration of ammonia nitrogen in urine of sheep on normal diets ranged widely from 0.26 to $4.15 \mathrm{mg} / \mathrm{ml}$ with a mean of $\mathrm{I} \cdot 66 \pm \mathrm{I}^{\circ} \cdot 09$ (SD) during a period of 8 months. In the range of urine $\mathrm{pH}$ of ruminants, most of the ammonia will be ionized to the ammonium ion. For example, at $\mathrm{pHs}$ of 8 and $8 \cdot 5$, the fraction of ammonia in the ionized form will be, respectively, 96 and $89 \%$. The concentration of ammonia in urine from sheep with urinary tract infection will be increased by bacterial breakdown of urea.

Other salts. The incidence of calculi in sheep produced by a calculogenic diet can be reduced by adding a variety of inorganic salts to the diet; sodium chloride (Elam, Ham \& Schneider, I957; Udall, I959, I962), ammonium chloride (Udall \& Chen Chow, 1965; Crookshank, Keating, Burnett, Jones \& Davis, I960; Bushman et al. 1967; Bushman, Emerick \& Embry, 1968), potassium chloride (Crookshank, 1966), potassium bicarbonate (Crookshank, 1966) and calcium chloride (Bushman et al. 
1967 , I968). However, these effects have not been found by all workers and it is more than likely that the protective nature of these dietary additions are not independent of the type of calculogenic diet and only limited conclusions about the efficiency of certain treatments can be drawn. Theoretically these dietary additions can reduce the supersaturation of a calculus-forming salt by increasing the volume of urine, by reducing the ionization of a relevant ion through changes in urine $\mathrm{pH}$ and ionic strength, by reducing the concentration of an ion by forming a soluble complex with that ion or by interfering with the absorption from the gut or the excretion by the kidney of a chemical element found in calculi.

In conclusion, it must be stressed that information about the aetiology of calculus formation in ruminants is limited by lack of knowledge on the degree of saturation of urine with the calculus-forming salts. Obtaining such information will be difficult but the recent introduction of new techniques gives hope for the future. Existing information suggests that the concentration of the trivalent phosphate ion and hence urine $\mathrm{pH}$ may be the dominating factor in the formation of phosphatic calculi and that the use of diets or dietary supplements which lead to more acid urine may be one of the more important means of reducing the incidence of calculus in ruminants.

\section{REFERENCES}

Bell, D. S. \& Kirk, K. F. (1935). Bull. Ohio agric. Exp. Stn no. 56r.

Boyce, W. H., Garvey, F. K. \& Norfleet, C. M. (1954). F. clin. Invest. 33, 1287.

Boyce, W. H. \& Swanson, M. (1955). F. clin. Invest. 34, I58I.

Bushman, D. H., Embry, L. B. \& Emerick, R. J. (1967). Ұ. Anim. Sci. 26, 199.

Bushman, D. H., Emerick, R. J. \& Embry, L. B. (1965). F. Nutr. 87, 499.

Bushman, D. H., Emerick, R. J. \& Embry, L. B. (r968). F. Anim. Sci. 27, 490.

Cornelius, C. E. (1963). Ann. N.Y. Acad. Sci. ro4, 638.

Cornelius, C. E., Moulten, J. E. \& McGowan, B. (1959). Am. F. vet. Res. 20, 863.

Crookshank, H. R. (1966). F. Anim. Sci. 25, 1005.

Crookshank, H. R., Keating, F. E., Burnett, E., Jones, J. H. \& Davis, R. E. (1960). F. Anim. Sci. 19, 595 .

Crookshank, H. R. \& Robbins, J. D. (1962). Nature, Lond. 196, 1343.

Elam, C. J., Ham, W. E. \& Dyer, I. A. (1959). F. Anim. Sci. 18, 383.

Elam, C. J., Ham, W. E. \& Schneider, B. H. (1957). Proc. Soc. exp. Biol. Med. 95, 769.

Elliot, J. S., Quaide, W. L., Sharp, R. F. \& Lewis, L. (1958). F. Urol. 8o, 269.

Emerick, R. J. \& Embry, L. B. (1963). F. Anim. Sci. 22, 5 I0.

Emerick, R. J. \& Embry, L. B. (1964). F. Anim. Sci. 23, 1079.

Fleisch, H. \& Bisaz, S. (x962). Am. F. Physiol. 203, 67I.

Gill, W. B., Finlayson, B. \& Vermeulen, C. W. (1959). 7. Urol. 82, 256.

Howard, J. E. (r962). Can. med. Ass. F. 86, roor.

Howard, J. E., Thomas, W. C., Barker, L. M., Smith, L. M. \& Wadkins, C. L. (1967). Fohns Hopkins med. F. 120, 119.

Joly, J. W. (1939). Seventh Congr. int. Soc. Urol. p. 77.

Jordan, R. M. (1953). F. Anim. Sci. 12, 670.

Lindley, C. E., Taysom, E. D., Ham, W. E. \& Schneider, B. H. (r953). F. Anim. Sci. 12, 704.

Marsh, H. (1961). F. Am. vet. med. Ass. 139, го 9.

McGregor, J., Robertson, W. G. \& Nordin, E. C. (I965). Br. F. Urol. 37, 518.

Nordin, B. E. C. \& Robertson, W. G. (1966). Br. med.F. i, $45^{\circ}$.

Packett, L. V. \& Coburn, S. P. (1965). Am. F. vet. Res. 26, I I z.

Packett, L. V. \& Hauschild, J. P. (1964). F. Nutr. 84, I85.

Puntriano, G. O. (1954). F. Am. vet. med. Ass. 124, 55.

Robbins, J. D., Kunkel, H. O. \& Crookshank, H. R. (1965). J. Anim. Sci. 24, 76.

Robertson, W. G., Peacock, M. \& Nordin, B. E. C. (1968). Clin. Sci. 34, 579.

Thomas, W. C. \& Howard, J. E. (1959). Trans. Ass. Am. Physns 72, 181. 
Udall, R. H. (1959). Am. F. vet. Res. 20, 423.

Udall, R. H. (1962). Am. F. vet. Res. 23, 1241.

Udall, R. H. \& Chen Chow, F. H. (1963). Ann. N.Y. Acad. Sci. 104, 612.

Udall, R. H. \& Chen Chow, F. H. (1965). Cornell Vet. 55, 538.

Vermeulen, C. W., Lyon, E. S. \& Fried, F. A. (1965). F. Urol. $94,176$.

\author{
Mycotoxins in ruminants \\ By M. C. LanCaster, Nuffield Unit for Laboratory Animal Pathology, \\ University of Edinburgh
}

\title{
Introduction
}

Mycotoxins have for long been associated with disease and death in animals, but because of the great variety of fungi present in animal feedstuffs and the detailed investigations needed to establish a causal relationship between mycotoxin and a clinical disease, few disease syndromes have been identified.

In this paper, it is proposed to consider three confirmed clinical diseases caused by mycotoxins, to review briefly their history and identification and to consider their biological effects in ruminants.

The three mycotoxins are ergot toxin, from the fungus Claviceps purpurea, sporidesmin from Pithomyces chartarum and aflatoxin from Aspergillus flavus. Of these, ergot toxin is the most familiar and has spectacular clinical effects; it causes one of the oldest diseases to be identified in the literature, but confirmed outbreaks of disease are rare in the UK. Sporidesmin, a primary hepatotoxin, is the causal agent of facial eczema of sheep in New Zealand. This is an economically important disease, and although it has been described and its causal agent the fungus Pichartarum is known, control under field conditions is still very difficult. Aflatoxins may be common contaminants of groundnut and cottonseed meals and are potent hepatocarcinogens for the rat.

Although these diseases present a primary problem in the ruminant, there is the secondary question of tissue residues and their possible hazard to man.

\section{Ergot poisoning}

Mycotoxins have long been associated with disease and death in ruminants; and probably the oldest accounts are of poisoning by ergot, the fungus Claviceps purpurea growing on cereals and in particular on rye. Some of the records of this disease go back for more than a century, but the evidence is not always very satisfactory (Barger, 1931).

In cattle, the diagnostic lesions are the development of gangrene of the extremities. There are many confirmed outbreaks of disease in ruminants. In one such severe outbreak involving a herd of forty-three cows and heifers in the UK, sixteen had severe gangrene of the extremities, but none aborted (Dring, 1955).

By feeding ergot to cattle in New Zealand, Cunningham, McIntosh \& Swan (1944) produced the clinical symptoms of gangrene of the extremities, but neither the milk or meat contained any toxic residues (Cunningham, 1949). These workers 